\title{
The role of personal tutoring in supporting the transition to university: experiences and views of widening participation sport students.
}

\section{Rick Hayman}

Northumbria University, UK

\section{Andy Coyles}

Northumbria University, UK

Karl Wharton

Northumbria University, UK

\section{Antony Mellor}

Northumbria University, UK

\section{Abstract}

Despite the large and diverse cohorts annually recruited to Higher Education sport programmes in the UK, research exploring sport students' experiences of transitioning into university is very limited. This study was conducted in response to several years of low retention and progression rates across first year sport degree programmes at a post-92 university in the UK. Through focus groups, the study explored the role played by the personal tutor in supporting effective transition of recently enrolled first year sport students from widening participation backgrounds. Most noticeably, the main contributory factors were found to be the nurturing of social integration and use of student-centred personal tutoring approaches to do so. The study further outlined how many widening participation sport students enter university with negative previous personal tutoring experiences and have limited understanding and misguided expectations of the role. The collective findings provide academic colleagues and university management with evidence of one model of effective support for a successful transition into university. Practical implications for widening participation students studying both sport and other degree subjects are presented, as are future research avenues and study limitations. 
Hayman, Coyles,

Wharton and Mellor
The role of personal tutoring in supporting the transition to university: experiences and views of widening participations sport students.

Keywords: higher education; personal tutoring; social integration; sport students; transition; widening participation.

\section{Introduction}

In the United Kingdom (UK), widening participation (WP) has become an established component of the government's political drive in addressing inequality of access to higher education (HE) for underrepresented student groups. The agenda has achieved relative success over recent decades across the UK university sector, as evidenced by significant growth in student numbers entering $\mathrm{HE}$ from non-traditional and socio-economically disadvantaged backgrounds. This includes those classified as vocational, mature, parttime or disabled learners, and those coming from low income households or deprived neighbourhoods (Younger et al., 2018). UK universities are now fully committed to WP and fair access, and for many, this is an integral part of their student recruitment (Jones and Lau, 2010). In England for example, application rates for 18-year-olds living in areas with historically low HE participation rates increased to the highest recorded levels in 2018 (Universities UK, 2018). However, an unfortunate consequence of the escalating size, diversity and profile of modern-day student populations has been the significant rise in university withdrawal rates during the first 12 months of enrolment (Tinto, 2012; Christie et al., 2013; Kahu and Nelson, 2018).

\section{Transitioning into university}

For many students across multiple subject disciplines, but especially those from WP backgrounds, failing to overcome both social and academic barriers to HE can overshadow the many opportunities a high quality university education can offer (Bennet et al., 2007; Gale, 2011; Devlin, 2013). Successful university transition is reflective of newly arrived students feeling they have settled promptly, confidently and happily, made new friends and networks, and developed a sense of belonging and identity with peers and 
academic staff (Wilcox et al; 2005; Farhat et al., 2017). However, a substantial research base clearly demonstrates how many find adjusting to social and academic demands as being a problematic and challenging aspect of early university life (Pillay and $\mathrm{Ngcobo}$, 2010; Lee and Gawson, 2011; Murtagh, 2012; Turner et al., 2017). Evidence also suggests how new HE students are more likely to disengage, underachieve and ultimately withdraw from their studies if they feel unsupported and when their expectations are not fully met or only partially addressed (Bennett et al., 2007; Leese, 2010; Byrne et al., 2012; Thomas, 2012).

It is also important to remember how many first-year undergraduates, including those studying sport programmes, have only ever experienced school and further education learning environments where numbers are typically much smaller, study is more structured and tutor-led, fewer teaching staff may be involved and where groups are small enough for everybody to know each other reasonably well (Allin et al., 2017). Strong evidence further demonstrates how these students, and particularly those from WP backgrounds, lack sufficient understanding of what HE level learning entails (Gamache, 2002; Lowe and Cook, 2003; Allin et al., 2017), and that many enter their studies feeling underprepared and overwhelmed by the teaching and assessment methods they are likely to encounter (Allin et al., 2017; Fahrat et al., 2017).

It is further well established that large numbers lack confidence and struggle with the sudden shift towards independent learning, have limited experience of collaborative learning and are initially hesitant to ask for guidance and support from academic staff (Murtagh, 2010; Thomas, 2012; Hockings et al., 2018; McMillan, 2013). Part-time, mature and working-class students are also known to find it more difficult when transitioning into $\mathrm{HE}$ and have higher non-completion rates than those from traditional backgrounds (Tinto, 2010; Rubin, 2012).

The study by Gill (2019) is one of the few to have explored the thoughts, feelings and perceptions of sports students on their forthcoming transition into university. Key study findings were that many expected to face numerous academic and social barriers upon entry, including increased workloads, difficulty completing assessments to expected 
standards and failing to become more independent learners. Hayman et al. (in press) examined the expectations, motivations, anticipated challenges and concerns of 334 first year sport degree students who had recently enrolled at an English post-92 university. Notable results included a significant shift towards vocational entry qualifications, the dominance of expectations around employability and a general lack in confidence to successfully integrate, both socially and academically. Overall, such findings emphasise how newly arriving students, including those studying sport, are now entering HE with multiple uncertainties, fears and concerns about transition, workload, independence and responsibility. This seems especially the case for those entering from WP backgrounds, who may require even greater guidance and support as they transition into HE and acclimatise to day-to-day student life.

\section{The University Personal Tutoring Role}

The benefits of personal tutoring in HE are widely acknowledged throughout the literature for their positive impact on a number of student satisfaction, engagement and attainment outcomes (Watts, 2011; Hagenauer and Violet 2014; McFarlane, 2016; Yale, 2019). Such benefits include supporting the transition from school or college into $\mathrm{HE}$, reinforcing learning in core academic modules, promoting the development of transferable skills, improving student retention and progression, helping to build self-confidence, social integration and sense of belonging, plus improving emotional well-being, student-staff relationships, career awareness and employability (Neville, 2007; Kim and Sax, 2009; Evans, 2013; Ross et al., 2014; Stork and Walker, 2015). It is widely acknowledged that personal tutors have a multifaceted and integral role to play in the academic, personal and professional development of their students, with robust approaches helping the latter to feel part of a learning community where support is readily available (Race, 2010). Primarily, they are responsible for providing a personalised approach to university life, which is often lost when students are part of large departments and schools where they can often feel isolated and remote. They also play a leading role in assisting students to better understand factors which contribute to successful student experience and can 
provide appropriate guidance, either directly or by signposting, to specialist student support and welfare services available within a university (Ghenghesh, 2018).

Academic staff have long reported on the lack of formal personal tutor training opportunities and the additional workload associated with the role (Barlow and Antoniou, 2007; Watts, 2011; McFarlane, 2016). They have expressed particular concern about the complex boundaries between academic and pastoral aspects of the personal tutoring role, where interpretations between individual tutors may differ, thus potentially leading to inconsistencies in student experience (Luck, 2010; Gubby and McNab; 2013). These findings suggest that regular professional development opportunities should be provided for all personal tutors so they can help their tutees adapt and cope within their new learning environments.

The findings of studies across various disciplines, including medicine, pharmacy and nursing, demonstrate how students perceive effective personal tutors as being approachable, enthusiastic, accessible, non-judgemental, good at signposting to other services, effective communicators and listeners, personable, caring and encouraging (Smith, 2008; Race, 2010; Calcagno et al., 2017; Ghenghesh, 2018; Yale, 2019). In their study exploring student nurses' personal tutor experiences, Braine and Parnell (2011) found the majority of responses to be mostly positive, but some respondents also felt the need for additional contact time, and guidance with personal development planning. The study by Laycock and Wisdom (2009) found effective personal tutoring played a contributing factor in raising student retention levels, whilst Owen (2002) highlighted how students liked and considered it good practice to maintain the same personal tutor at all stages of their university life. More recently, McFarlane (2016) found those students who interacted more frequently with their personal tutor than their peers encountered higher satisfaction and progression rates.

Many students have mixed experiences of personal tutoring, sometimes viewing it as disorganised and poorly integrated within the curriculum (Hixenbaugh et al., 2006). There is also evidence within the literature demonstrating how undergraduate students lack a general understanding of core personal tutor roles and responsibilities (Myers, 2008), and 
feel uncertainty over who best to approach when encountering academic and/or personal issues (Basset et al., 2014). Stephen et al. (2008) reported how after an initial introductory meeting in first year induction, some undergraduate students had no further contact with their personal tutor during the whole of their university education. We also know that students can feel intimidated by their personal tutor, thus tending to have irregular contact with them (Malik, 2000), and that they do not always fully understand the tutor's value, both in the present and future, in supporting their academic success, providing references and offering career guidance (Gubby and Nicole, 2013; Ghenghesh, 2018)

\section{Research Context}

The transition into HE involves a complex process of change, which some students manage more successfully than others (Briggs et al., 2012; Richardson and Tate, 2013; Taylor and Harris-Evans, 2018; Gravett, 2019). It is now well recognised in the literature that students entering HE from non-traditional backgrounds especially may struggle to adapt to a new HE environment (e.g. Reay, et al., 2010; Allin et al., 2017). Yet, despite the large and diverse cohorts annually recruited to HE sport programmes in the UK, the proposed study will be the first to explore their experiences and views of transitioning into university. This small exploratory study was conducted at a university in England (hereafter referred to using the pseudonym RM). RM has long encountered retention issues with first year sport student cohorts, especially those characterised as having entered from widening participation backgrounds. A significant proportion of newly arriving RM sport cohorts now enter from backgrounds not typically considered traditional.

Examples include those who commute daily, enter with vocational qualifications, are from low income families, are the first in their family to enter HE or who come from neighbourhoods where HE is not a common destination (Crosling, et al., 2008; Turner et al., 2017).

WP and fair access are high priorities at RM and they are instrumental in the university's approach to attracting talented and high-quality students regardless of background (RM 2020-21 to 2024-25 Access and Participation Plan). The RM personal tutoring system has 
been designed to play an integral part in the academic, personal and professional development of all its students. Key personal tutor roles and responsibilities are to publicise and communicate their contact details, office hours and meeting arrangements to each of their tutees so they are aware of how and when they can make contact and meet personally. Within the sport department, a strong emphasis has been placed on better supporting newly arrived students to settle and adapt by developing their social integration and creating a sense of engagement and belonging in their new learning community. For example, staff and their tutees establish a relationship and get to know each other at the very start of their university life by undertaking a range of team building and practical sport activities together during programme induction. The personal tutor also monitors their tutees' academic progress and provides support for those who are not progressing satisfactorily through regular face to face meetings.

As far as possible, the personal tutor allocated in year one will stay with the same student throughout their time at RM, thus allowing for an effective and longstanding professional relationship of support to be developed. This is particularly important when it comes to completing reference requests for further study or job applications. If a member of staff changes role or leaves RM, a 'hand over' of tutees to the new personal tutor occurs. Students are made aware well in advance of any change to their personal tutor and are able to request to change if they wish from the one allocated, without having to provide reasons. As the role can involve complex issues when dealing with students, a range of short personal tutor training courses are available. These include 'Building Positive Relationships', 'Responding to Student's Academic Concerns', 'Preparing and Delivering Feedback' and 'Presenting your Best Self'. Personal tutor related activities are also embedded into a core year one module to raise the currency and significance of the role with students.

\section{Theoretical Framework and Study Aims}

Alexander Astin (1984) proposed a student engagement theory based on student 'involvement', which he defined as 'the amount of physical and psychological energy that 
the students devotes to the academic experience' (Astin, 1984, p. 297). The theory, which has made a significant contribution to student engagement literature, policy and practice, proposes that the more students feel academically and socially involved, the better their overall learning experience will be and the less likely they are to drop out or fail. Thus, within the context of Student Involvement Theory, a highly involved student is one who devotes considerable effort to studying, spends time on campus, participates actively in student organisations and interacts frequently with other students and academic staff. Alternatively, a typically uninvolved student will show signs of neglecting their studies, spend little time on campus, abstain from extracurricular activities and have infrequent contact with fellow students and academic staff (Astin, 1999).

Over the past three decades, a range of studies have both supported and disputed various components of this body of work. For example, the theory has received criticism for the general and basic assumptions it proposes about involvement plus its heavy emphasis on only traditional, full-time and residential students from North America. Furthermore, the relevance of the theory to those entering $\mathrm{HE}$ from non-traditional backgrounds, including mature, part-time, WP, disabled and working students is uncertain and warrants further scrutiny and investigation.

The recent growth in personal tutoring research across the HE sector has been well received and is an encouraging step forward. However, criticism has been made of the heavy emphasis on atheoretical studies undertaken with small sample sizes from traditional backgrounds across a narrow range of disciplines (e.g., nursing). Therefore, using Student Involvement Theory (Astin, 1984) as a guiding theoretical framework, the primary objective of this study was to investigate the role played by personal tutors in supporting effective transition of recently enrolled first year WP sports students at RM.

\section{Methods}

Focus groups were the chosen data collection tool in this qualitative study because they enable the gathering then questioning of several individuals about their attitudes to, 
Hayman, Coyles, Wharton and Mellor
The role of personal tutoring in supporting the transition to university: experiences and views of widening participations sport students.

experiences of and thoughts on a specific concept or topic (Leung \& Savithiri, 2009). Key strengths include their flexible nature and opportunity for multiple voices to be heard simultaneously. They have become a popular investigative technique in recent years across several subjects, including health (Banerjee et al., 2019) and sport (Fedderson et al., 2020). Previous research by Yale (2019) also employed focus groups to explore first year undergraduate psychology students' personal tutoring experiences.

Each focus group was completed at a convenient time and location for all consenting participants. In all cases, this was within a safe, private and comfortable room within the RM campus. When undertaking qualitative research, it is important that the interviewer quickly builds trust and rapport with interviewees, so they feel reassured and relaxed to freely discuss topics they feel appropriate. The lead author has an established background in undertaking qualitatively based research within HE settings, which he used to aid the process of establishing a positive and empathetic bond with participants (Patton, 2002). He had also lived the WP university student experience himself, which provided valuable insight and understanding into likely barriers and vulnerabilities faced by the participants. The focus group questions were pilot tested by four WP second year undergraduate sports students who each had experience of engaging with the RM personal tutor process. This confirmed an approximate completion time of 40 minutes, with all wording and terminology considered appropriate and understandable for first year cohort students.

Four face-to-face focus groups, each comprising between seven and nine participants and lasting from 35 to 50 minutes, took place over a five-day period in December 2018. Every attempt was made to guide participants through a series of open-ended questions which probed their experiences and views of personal tutoring and the consequent role it had played in supporting their transition into RM. The first and second authors undertook the role of facilitators rather than interviewers in each focus group, freely encouraging participants to interact with each other and to assist them in conveying their unique experiences. To ensure participants felt at ease to share personalised and exclusive accounts, each focus group started with an informal discussion about primary motivations for attending RM and their highlights thus far (Rapley, 2004). Immediately prior to the focus groups commencing, the first author reminded all participants how there were no 
Hayman, Coyles, Wharton and Mellor
The role of personal tutoring in supporting the transition to university: experiences and views of widening participations sport students.

correct or incorrect answers and that everyone's contributions were important, even if they did not match those of others present.

\section{Sample}

During late November 2018, all newly arrived first year undergraduate sports students were invited to participate in the study. Once institutional ethical clearance was granted, an initial recruitment email briefly outlining the study aims, objectives, inclusion criteria and procedures to follow, along with participant information sheet and consent form, were communicated via the online Blackboard portal. This specifically explained how the research team were wishing to recruit and then interview participants in small focus groups, who were categorised in one or more of the following WP student criteria: (1) first generation (2) commuter (3) BTec entry qualification. (The Business and Technology Education Council (BTec) is a vocationally based qualification which enables students to gain skills and knowledge in their subject area, then apply them in real-life and applied scenarios.)

A self-selecting sampling approach was adopted, which resulted in 32 (male = 14; female =18; mean age $=19.2$ ) eligible full-time first year undergraduate sport students agreeing to participate in the study. The majority $(77 \%)$ were the first from their immediate family to attend university. $88 \%$ had completed a BTec sport qualification (either at college or school sixth form). Over half (63\%) were residing at home and commuting daily into university. All consenting participants were assigned numerical pseudonyms to protect anonymity and were free to withdraw from the study at any time without providing any reasons. No participant was reimbursed for their time or travel.

\section{Analysis}

Each focus group was recorded, transcribed verbatim and subjected to the thematic analysis guidelines published by Braun and Clarke (2006). Example focus group questions 
included 'Can you give some examples of what personal tutor experiences you have found useful?' and 'Are there any benefits you feel have come from your personal tutor?'. To gain further insight, supplementary probing was employed. Examples included 'Why was that so specifically useful?', 'What other ways could this have been undertaken?', 'Why do you think it made you feel this way?' and 'When did you start to appreciate what had happened?'. This ad-hoc questioning approach ensured participant centeredness, making it possible to follow up conversations where appropriate (Lincoln and Gubba, 1985). A copy of all focus group questioning schedules used in the study are available on request from the first author.

All four scripts were read multiple times by the first and second authors, with notes reflecting theme statements and their meanings placed within margins. The same authors then independently annotated each interview transcript with their personalised thoughts and interpretations of the data. Thematic coding employed an inductive approach to allow for lower order themes to be derived. There were some minor discrepancies between the two separate coding results, but all were discussed and promptly resolved. Primary associations and connections based on similarities and patterns between derived themes were made, resulting in the generation of four main themes. Once finalised, direct quotes representing each theme were selected. The final analysis stage involved developing written accounts from identified themes which were reviewed and redrafted several times.

\section{Findings}

The findings are presented under four key themes which reflect the experiences and views of participants in the study. Participant and focus group (FG) numbers are presented in parentheses (e.g., P1, FG1 reflects participant 1 in focus group 1).

\section{The personal tutor as a lynchpin for social integration}

All participants felt their RM personal tutor had positively supported their transition into university. When probed further, the majority discussed having felt persistently anxious 
and daunted at the very prospect of staring university. Several talked at length about their worries of 'not fitting in', 'making no friends' and 'feeling isolated'.

I had a real fear of not settling in at all when I first arrived. I was so nervous over the summertime and lead up to starting. (P3, FG1)

I remember I was feeling really stressed when I first arrived at university about not making friends with anyone or being able to cope with the work. (P6, FG4)

But the social support their personal tutor provided during their early months of studying at RM played a significant role in alleviating such challenges and concerns. When asked to elaborate further, some talked openly about the friendly and personalised welcoming they encountered.

I am very grateful for the time and effort they (personal tutor) gave in the first few days when I was feeling a bit low and down in the dumps. (P8, FG1)

From my first day, they (personal tutor) made me feel welcome and just seemed to go out of their way to help me settle in by introducing me to other lecturers and people on my course.(P2, FG2)

They (personal tutor) asked me about how I ended up at university and what type of things I liked doing and came across as such a nice bubbly person who wanted to help me fit in. (P6, FG2)

As focus groups progressed, participants continued to talk positively about their RM personal tutor in multiple ways. It was particularly noticeable how their reassuring, trusting, and caring approaches to personal tutoring were very well received and made positive lasting impressions. This particularly helped in supporting participants to feel more settled, better integrated and that they belonged as part of RM from the very beginning of their studies. 
I was really struggling in the first couple of weeks and missing friends at home, So I went to speak with my personal tutor and they told me how they had felt exactly the same when they went to university and that really helped to cheer me up. (P5, FG1)

I was feeling a bit apprehensive after the first week so I went to see my personal tutor and they were so helpful and reassuring and sat me down and explained how this was natural and I would settle just fine and get to know people. (P2, FG4)

Several went on to discuss further how their personal tutor had supported them to build networks and form friendships with a variety of people across RM, including fellow peers and academic staff. The following quotes demonstrate the positive impact of these actions and how they actively supported their social integration into university life.

During the induction week, I got to know my personal tutor and their other students who were new like me and I am friends with some of them now and we spend time together on campus and we even go training together sometimes. (P2, FG3)

When I first met my personal tutor at induction, they took an early interest in me and the other students in our group and kept asking questions about us all and making us laugh. (P6, FG3)

\section{The need for student centred tutoring}

Participants talked favourably about their encounters of student-centred personal tutoring at RM and the important role it had played in supporting their transition into HE. It was especially noticeable how such approaches supported them in feeling gradually more confident, prepared and connected, both socially and academically. They fully respected and valued their RM personal tutor and the range of activities and roles they undertook. 
I can pretty much talk to my personal tutor anytime I need about anything and they help and show an interest in me rather than it just being one of their jobs. (P5, FG1)

My relationship with my personal tutor is great. They are easy to talk to and someone who comes across as if they did not have to be there for me when I need them but more like they want to spend time with me. (P9, FG1)

I would say my personal tutor is on my level, like they are approachable and show they care about me. (P4, FG2)

I find I can speak with them (personal tutor) easily and they understand what I am talking about. (P7, FG3)

All participants felt generally comfortable in approaching their RM personal tutor for guidance and direction concerning both academic and non-academic matters. The informal, relaxed and reassuring nature of open-door student-led 'drop in' appointments were very popular. Such an approach helped participants to establish close contact relationships with their personal tutor and led to them feeling progressively more engaged with daily RM life.

I have a good bond with my personal tutor and feel comfortable in going to ask them questions if I am too sure about somethings like referencing or part of a lecture I did not fully understand. (P2, FG2)

Mine (personal tutor) often messages me out of hours just saying they are always there if I need to chat through anything which is thoughtful and kind and motivates me to want to do well. (P8, FG2)

My personal tutor has an open-door policy which is a good thing and nice and relaxed so I do not have to book and have flexibility. (P6, FG3) 
RM personal tutors were complimented for being empathetic, helpful, caring, humorous and highly organised. Their kind demeanour and ability to motivate and include participants from the very start of their post enrolment RM experience was firmly established, as was their ability to recognise and celebrate the achievements of all, regardless of background.

After the first personal tutor meeting, I left feeling I mattered and liked how they gave me a bit of background on their family and hobbies which gave off a nice impression. (P6, FG1)

They (personal tutor) have helped me in making the jump from college to being more independent at university and the belief that I was not going to struggle. (P3, FG3)

They heard I was keen to complete my next coaching qualification and took interest in why I decided to do so and where would it take place. (P5, FG4)

They (personal tutor) have an interest in what I do in and out of university and this makes me want to go and see them for a chat rather than have to go and see them and for it to be very formal. (P6, FG4)

\section{The influence of negative pre-university personal tutoring experiences}

Some participants entered RM having encountered negative previous personal tutoring experiences within the school and college system. Several openly described their frustrations and reasons to why they had previously disengaged with the personal tutor role.

It was like college tutors were contacting everyone saying we should book a meeting with them to see how things were going but it was all a bit forced and like they had only been told to make contact by the managers which put me off. (P7, FG1) 
Hayman, Coyles, Wharton and Mellor
The role of personal tutoring in supporting the transition to university: experiences and views of widening participations sport students.

Going to see your personal tutor was not taken so seriously by anybody in my college, so I only ever arranged a few meetings over the two years I was there. (P3, FG2)

My personal tutor at college went on maternity leave and so I was allocated a new one but I could not find that new person and then it changed again in the matter of a few weeks, so that was a complete nightmare. (P5, FG2)

My college personal tutor shared an office with some other staff and I once went to see them with an issue I wanted to speak about in private but these other people were working at their desks so I did not end up mentioning the real reason I wanted to see them about. (P6, FG4)

Participants deemed the personal tutor role in school and college settings to be excessively formal, often disorganised and insufficient in appropriately supporting them for a life in HE. Many disliked the traditionally directive and tutor-led models of personal tutoring they received. Several participants talked about their struggles in trying to develop a positive rapport and connection with their personal tutor.

I met with my personal tutor at college only once because I did not really hit it off with them. (P1, FG2)

I had someone as a personal tutor at college who made me feel like I was coming across as an inconvenience when I asked them for a meeting. (P2, FG1)

I had made my mind up after the first meeting that I was not so bothered about using my personal tutor because it all just seemed like I had to go there to tick a box and talk about things we had done in other classes. (P2, FG2) 
The personal tutor system at college was not that good for me as it was quite matter of fact and concentrated on things like making sure I was attending and submitting work on time. (P6, FG2)

\section{Mistaken expectations and understanding of the personal tutor role}

Participants had limited knowledge about the very concept of personal tutoring upon their arrival at RM. Many were unaware of the multiple support mechanisms the role provides and the positive impact it can have upon their academic, personal and professional development. The majority had distorted views and expectations about the personal tutor role. For example, several had always fully anticipated their personal tutor to be freely available to support with any issues they faced, especially those relating to summative assessment and attendance.

I think personal tutors should be willing to speak to students no matter when or what time of day we need them. (P3, FG1)

I came here (RM) thinking that lessons should be attended but a meeting with your personal tutor looked as more voluntary and only needed if you have a problem. (P5, FG2)

I found at college I was having to meet with them (personal tutor) but did not know what I was supposed to say or talk about. (P2, FG3)

Several discussed how their early RM personal tutoring experiences were positive, which differed considerably from previous experiences within school and college settings. Many explained how they entered RM sceptical about the role. When probed further, they explained having become previously accustomed to only ever approaching their personal tutor for academic related issues, of which most were assessment support related.

In college, I only really went to see her (personal tutor) for academic reasons and mainly to get help on assessments. (P7, FG2) 
Hayman, Coyles, Wharton and Mellor
The role of personal tutoring in supporting the transition to university: experiences and views of widening participations sport students.

I viewed my personal tutor as the first point of contact in terms of getting assessment support and sorting any problems, like helping you with completing work. (P8, FG2)

I have only ever contacted them (personal tutor) when I was struggling and wanted some advice about assignments. (P2, FG2)

I saw my college personal tutor as someone who was there to give assessment advice. (P3, FG3)

I would get in touch with my personal tutor sometimes only when I needed some help for an assessment. (P4, FG3)

Participants also discussed the importance of sufficiently educating newly arriving student cohorts from the very start of their RM experience about the aims and objectives of the university personal tutoring system and to reinforce it as they pass through their programme of studies.

I first met my personal tutor in the induction week and we talked about what was expected from me in terms of responsibility and how I should be in close contact with them all through the time of my degree because they could help me get work experience and provide references. (P1, FG7)

The session I had with my personal tutor in freshers was good as it set out what they were there for and some of the things they could help me with. (P4, FG4)

\section{Discussion}

To our knowledge, this study was the first which specifically explored the role played by personal tutoring in supporting the transition of first year WP sport students into HE. The 
findings from a large research body across several subject disciplines clearly demonstrate how WP background students have historically encountered multiple challenges and difficulties in both entering and succeeding in HE (Reay et al., 2010). Most notably, factors relating to social integration including difficulties in making new friends, adjusting to university culture and struggling to cope with homesickness are prominent in the decision to leave or remain at university in the first few months post enrolment (Thomas, 2012; Alliin et al., 2017). Our findings in this study demonstrated how RM undergraduate sport programmes continue to recruit a varied demographic of learners, including large numbers from non-traditional, first generation and vocational backgrounds, of which many no longer leave home but instead commute daily into university. A key finding of this study was how student-centred personal tutoring approaches played a leading role in helping first-year WP sport students to gain confidence, feel settled and reassured, to integrate socially with peers and academic staff and become familiarised with university culture.

It was notable how personal tutoring acted as a key support mechanism in enhancing the first-year university transitioning experience. We found most participants to be strategic learners on entry (e.g., assessment focussed) and wanting relaxed, friendly, informal discussions with personal tutors on an ad-hoc and open-door policy basis. They wanted the same personal tutor across the whole student life cycle and particularly liked getting to know them, both professionally (e.g., awareness of their research expertise) and nonprofessionally (e.g., insight into current and previous hobbies, sports played and coaching commitments). Participants expected frequent and immediate access to their personal tutor, and for them to be approachable and effective communicators, enthusiastic towards them as individuals, to teach them regularly and to provide frequent and high quality assessment support and guidance when necessary, all features highlighted previously by Race (2010). Another key finding was the need for newly arriving sport students to be sufficiently educated about the very concept of university level personal tutoring and the consequent impacts it can have on satisfaction and achievement.

This study illustrates Astin's Student Involvement Theory by demonstrating how sport students from WP backgrounds can better transition into university with an effective personal tutor, who not only assists with academic study questions, but also helps them 
acculturate to university. Students felt socially and academically engaged, and generally happy and settled within their new surroundings. They especially wanted to interact frequently with their personal tutor and utilise the tutor's specific knowledge to support their transition into university. A characteristic specific to sport students is that many are/have been used to being coached or mentored in their respective sport which often goes above and beyond their sporting environment, hence sport clubs are social fabric of local communities (Eime et al., 2013). This might transfer into the academic environment where they would be in favour of such a relationship with a significant other (e.g. their personal tutor) but further research is needed on this.

Several implications for personal tutors to support effective transitioning of WP sports students into HE emerged from the study. Firstly, they should expose them to regular opportunities to enhance sociability in welcoming and reassuring environments. The focus of this personalised approach should be on supporting students to build relationships, seek out connections and develop a sense of belonging with their course and academic peers, both within and outside of formal curriculum settings. Student centred approaches to personal tutoring are highly recommended as they can help learners to feel valued, understood and part of university life from day one. Ensuring students do not feel daunted by their personal tutor, and that they are sufficiently educated on the role and its value are also essential.

We further propose that students should be made fully aware of how their personal tutor can assist them to better understand factors which contribute to successful student experience and to provide appropriate guidance, either directly or by signposting, to appropriate advice and support available within a university. Therefore, a useful strategy may be to provide targeted professional development activities for academic staff. This will enable them to further develop explicit awareness of their role as a personal tutor and to fully appreciate how it extends much beyond the traditional view of seeing students only when issues arise (Yale, 2019).

This study was not without limitations. Although the recall period was short, we relied on retrospective recollections to explore participant's experiences and views of personal 
tutoring, which may be liable to lapses of memory. Focus groups were conducted relatively early in each student's personal tutoring experience, and the short study period may have limited the likelihood of encountering negative factors. The power relationship of tutors to students may have also played an influencing factor in the largely positive nature of findings. Participants may have chosen not to disclose any negative comments or concerns. Validation of participant accounts with those from their personal tutor would have been advantageous. The sample was homogenous, thus limiting generalisability of findings. Data collection occurred relatively early (week 10) in the participants' HE life, hence, follow up focus groups at the end of year one may have unearthed further important findings.

It is important to note how all RM personal tutors are allocated sufficient capacity within their workloads to undertake the role, thus providing valuable time for them to sustain regular face to face and online contact with their tutees. This approach appears successful in strengthening the relationships and rapport initially formed during induction and early stages of the academic year. Self-selection bias plus failure to provide participants with opportunity to corroborate the accuracy of their personal tutoring experiences through member checking were further study weaknesses. Nevertheless, the study findings provide a firm foundation for future personal tutoring research to build upon. For example, longitudinal studies utilising regular semi-structured interviews and self-report diaries would enable participants to discuss their personal tutoring experiences frequently over extended time periods (e.g., every 4-6 months). Such research may help to identify any key differences between those who encounter a successful transition into university with those who do not.

\section{Conclusion}

The HE sport discipline is one which continues to recruit high numbers of WP students annually from diverse backgrounds. This study fills a gap in the literature and provides evidence on the role played by the personal tutor in supporting the transition of first year WP sport students into a post-92 UK university. Astin's theory was found to be a useful 
starting point to frame and explore engagement and involvement of the whole student cohort. Most noticeably, the main contributory factors to a successful transition were the promotion of social integration through student-centred personal tutoring approaches. Additionally, our findings are the first to suggest that participants entered HE with negative previous personal tutoring experiences from school and college, which created a very distinct set of student expectations. In our experience, tutors devoted some considerable time and energy re-setting these. It appears personal tutors' sustained efforts to establish rapport with tutees were strongly influenced by their sport coaching backgrounds. This is an important finding and has implications for university leadership teams who may consider drawing consciously on the practices of coaching to underpin future personal tutoring policy and procedures. The collective study findings provide personal tutors working within and outside of sport subjects with evidence of how one subject group effectively supported the transition of a diverse student population into university. Longer term benefits may include improved retention and progression outcomes, increased proportions of students obtaining good honours awards, enhanced student satisfaction and improved employability rates.

\section{Acknowledgements}

The authors wish to thank all consenting participants for their time, generosity and insight throughout the data collection period.

\section{Author details}

Dr Rick Hayman is the Health and Life Sciences Faculty Director for Access and Participation at Northumbria University.

Mr Andy Coyles is a Senior Lecturer with the Department of Sport, Exercise and Rehabilitation at Northumbria University. 
Mr Karl Wharton is Head of Subject for Sport Development, Sport Management and Sport Coaching within the Department of Sport, Exercise and Rehabilitation at Northumbria University.

Dr Antony Mellor is the Engineering and Environment Faculty Director for Student Satisfaction and Engagement at Northumbria University.

\section{References}

Astin, A. (1984) 'Student involvement: a developmental theory for higher education', Journal of College Student Personnel, 25, pp. 297-308.

Allin, L., Coyles, A. and Hayman, R. (2017) 'Exploring social integration of sport students during the transition to university', Journal of Perspectives in Applied Academic Practice, 5, pp. 31-36.

Astin, A. (1999) 'Student involvement: a developmental theory for higher education. Journal of College Student Development, 40, pp. 518-529.

Banerjee, S., Semper, K., Skarparis, K., Naisby, J., Lewis, L., Cucato, G., Mills, R., Rochester, M. and Saxton, J. (2019) 'Patient perspectives of vigorous intensity aerobic interval exercise prehabilitation prior to radical cystectomy: a qualitative focus group study', Disability and Rehabilitation. 14, pp. 1-8.

Barlow, J. and Antoniou, M. (2007) 'Room for improvement: the experiences of new lecturers in higher education', Innovations in Education and Teaching International, 44 , pp. $67-77$.

Basset, J., Gallagher, E. and Price, L. (2014) 'Personal tutors' responses to a structured system of personal development planning: a focus on feedback', Journal for Education in the Built Environment, 9, pp. 22-34. 
Hayman, Coyles,

Wharton and Mellor
The role of personal tutoring in supporting the transition to university: experiences and views of widening participations sport students.

Bennet, R., Kottasz, R. and Nocciolino, J. (2007) 'Catching the early walker: an examination of potential antecedents of rapid student exit from business related undergraduate degree programs in a post-1992 university', Journal of Further and Higher Education, 31, pp. 347-364.

Braine, M. and Parnell, J. (2011) 'Exploring student perceptions and experiences of personal tutors', Nurse Education Today, 31, pp. 904-910.

Braun, V. and Clarke, V. (2006) 'Using thematic analysis in psychology', Qualitative Research in Psychology, 3, pp. 77-101.

Briggs, A., Clark, J., and Hall, I. (2012) 'Building bridges: understanding student transition to university' Quality in Higher Education, 18, pp. 3-21.

Byrne, M., Flood, B., Hassall, T., Joyce, J., Montano, J., Gonzalez, J. and TournaGermanou, E. (2012) 'Motivations, expectations and preparedness for higher education: a study of accounting students in Ireland, the UK, Spain and Greece', Accounting Forum, 36, pp. 134-144.

Calcagno, L., Walker, D. and Grey, D. (2017) 'Building relationships: a personal tutoring framework to enhance student transition and attainment', Student Engagement in Higher Education Journal, 1, pp. 88-99.

Crosling, G., Thomas, L. and Heagney, M. (2008) Improving student retention in higher education: the role of teaching and learning. London: Routledge.

Devlin, M. (2013) 'Bridging socio-cultural incongruity: conceptualising the success of students from low socio-economic status backgrounds in Australian higher education', Studies in Higher Education, 38, pp. 939-949. 
Eime, R., Young, J., Harvey, J., Charity, M. and Payne, W. (2013) 'A systematic review of the psychological and social benefits of participation in sport for children and adolescents: informing development of a conceptual model of health through sport', International Journal of Behavioral Nutrition and Physical Activity, 10, pp 98-119.

Evans, J. (2013) 'Personal tutor support from the start reduces student attrition', Nursing Standard, 27, pp. 6.

Farhat, G., Bingham, J., Caulfield, J. and Grieve, S. (2017) 'The academics project: widening access and smoothing transitions for secondary school pupils to university, college and employment', Journal of Perspectives in Applied Academic Practice, 5, pp. 23-30.

Gale, T. (2011) 'Expansion and equity in Australian higher education: three propositions for new relations', Discourse: Studies in the Cultural Politics of Education, 32, pp. 669685.

Gamache, P. (2002) 'University students as creators of personal knowledge: an alternative epistemological view', Teaching in Higher Education, 7, pp. 277-293.

Ghenghesh, P. (2018) 'Personal tutoring from the perspectives of tutors and tutees', Journal of Further and Higher Education, 42, pp. 570-584.

Gubby, L. and Nicole, M. (2013) 'Personal tutoring from the perspective of the tutor', Capture, 4, pp. 7-16.

Hagenauer, G. and Volet, S. (2014) 'Teacher-student relationship at university: an important yet under-researched field', Oxford Review of Education, 40, pp. 370-388.

Hayman, R., Coyles, R. and Allin, L. (in press) 'The profile of higher education sport students in England: implications for successful transition and effective teaching and learning practice', Innovative Practice in Higher Education. 
Hayman, Coyles, Wharton and Mellor
The role of personal tutoring in supporting the transition to university: experiences and views of widening participations sport students.

Hixenbaugh, P., Pearson, C. and Williams, D. (2006) 'Student perspectives on personal tutoring: what do students want?', In: Thomas L and HixenbaughP (eds) Personal Tutoring in Higher Education. (pp. 45-56). Stoke-on-Trent: Trentham Books.

Hockings, C., Thomas, L., Ottaway, J. and Jones, R. (2018) 'Independent learning: what we do when you are not there', Teaching in Higher Education, 23, pp. 145-161.

Jones, N. and Lau, A. (2010) 'Blending learning: widening participation in higher education', Innovations in Education and Teaching International, 47, pp. 405-416.

Kim, Y. and Sax, L. (2009) 'Student-faculty interaction in research universities: differences by student gender, race, social class, and first-generation status', Research in Higher Education, 50, pp. 437-459.

Laycock, M. and Wisdom, J. (2009) 'Personal tutoring in higher education - where now and where next? a literature review and recommendations', Staff and Educational Development Association, SEDA Specials.

Leese, M. (2010) 'Bridging the gap: supporting students into higher education', Journal of Further and Higher Education, 34, pp. 239-251.

Lincoln, Y. and Gubba, E. (1985) Naturalistic inquiry. London: Sage.

Lowe, H. and Cook, A. (2003) 'Mind the gap: are students prepared for higher education?', Journal of Further and Higher Education, 27, pp. 53-76.

Luck, C. (2010) 'Challenges faced by tutors in higher education', Psychodynamic Practice: Individuals, Groups and Organisations, 16, pp. 273-287.

Leung, F. and Savithiri, R. (2009). 'Spotlight of focus groups', Canadian Family Physician, 55, pp. 218-219. 
Hayman, Coyles, Wharton and Mellor
The role of personal tutoring in supporting the transition to university: experiences and views of widening participations sport students.

Malik, S. (2000) 'Students, tutors and relationships: the ingredients of a successful student support scheme', Medical Education, 34, pp. 635-641.

McFarlane, K. (2016) 'Tutoring the tutors: supporting effective personal tutoring', Active Learning in Higher Education, 17, pp. 77-88.

Myers, J. (2008) 'Points for debate: is personal tutoring sustainable? comparing the trajectory of the personal tutor with that of the residential warden', Teaching in Higher Education, 13, pp. 607-611.

McMillan, W. (2013) 'Transition to university: the role played by emotion', European Journal of Dental Education, 17, pp. 169-176.

Murtagh, L. (2010) 'They give us homework! transition to higher education: the case of initial teacher training', Journal of Further and Higher Education, 34, pp. 405-418.

Murtagh, L. (2012) 'Enhancing preparation for higher education', Practitioner Research in Higher Education, 6, pp. 31-39.

Neville, L. (2007) 'The personal tutor's handbook' Basingstoke: Palgrave Macmillan.

Owen, M. (2002) 'Sometimes you feel you're in niche time: the personal tutor system - a case study', Active Learning in Higher Education 3, pp. 7-23.

Patton, M. (2002) Qualitative research and evaluation methods. Thousand Oaks: Sage.

Pillay, A. and Ngcobo, H. (2010) 'Sources of stress and support among rural based first year university students: an exploratory study', South African Journal of Psychology, 49 , pp. 234-240. 
Race, P. (2010) Making Personal Tutoring Work. Leeds: Leeds Met Press.

Rapley, T. (2004) 'Interviews', In Seale, C., Gobo, G., Gubrium J. and Silverman, D. (Eds.), Qualitative research practice, (pp.15-33). London: Sage.

Reay, D., Crozier, G. and Clayton, J. (2010) 'Fitting in or standing out: working-class students in UK higher education', British Educational Research Journal, 36, pp. 107124.

Ross, J. Head. K., King, L. Perry, P. and Smith, S. (2014) 'The personal development tutor role: an exploration of student and lecturer experiences and perceptions of that relationship', Nurse Education Today, 34, pp. 1207-1213.

Rubin, A. (2012) Statistics for evidence-based practice and evaluation. Belmont, California: Cengage Learning.

Smith, E. (2008) Personal tutoring: an engineering subject centre guide. York: Higher Education Academy.

Stephen, D. O'Connell, P. and Hall, M. (2008) 'Going the extra mile - firefighting or laissez faire? re-evaluating personal tutoring relationships within mass higher education', Teaching in Higher Education, 13, pp. 449-460.

Stork, A. and Walker, B. (2015) Becoming an outstanding personal tutor: supporting learners through personal tutoring and coaching. Northwich: Critical Publishing.

Thomas, L. (2012) Building student engagement and belonging in Higher Education at a time of change: a summary of findings and recommendations from the What Works? Student Retention \& Success programme. Paul Hamlyn Foundation and the Higher Education Academy. 
Tinto, V. (2012) 'Moving from theory to action: a model of institutional action for student success', In A. Seidman (Ed.), College student retention: formula for student success $\left(2^{\text {nd }}\right.$ ed.). Plymouth: Rowman \& Littlefield.

Turner, R., Morrison, D., Cotton, D., Child, S., Stevens, S., Nash, P. and Kneale, P. (2017) 'Easing the transition of first year undergraduates through an immersive induction module', Teaching in Higher Education, 22, pp. 805-821.

Watts, T. (2011) 'Supporting undergraduate nursing students through structured personal tutoring: some reflections', Nurse Education Today, 31, pp. 214-218.

Wilcox, P., Winn, S. and Fyvie-Gauld, M. (2005) 'It was nothing to do with the university, it was just the people: the role of social support in the first-year experience of higher education', Studies in Higher Education, 30, pp. 707-722.

Yale, A. (2019) 'The personal tutor-student relationship: student expectations and experiences of personal tutoring in higher education', Journal of Further and Higher Education, 43, pp. 533-544.

Younger, K., Gascoine, L., Menzies, V. and Torgerson, C. (2018) 'A systematic review of evidence on the effectiveness of interventions and strategies for widening participation in higher education', Journal of Further and Higher Education, 42, pp. 132. 